\title{
Crónicas de Roma
}

\author{
por Abraham Valdelomar
}

\section{LAS SOMBRAS DEL ESPIRITU}

Hay dos Romas: La Roma del Baedeker, donde los turistas hacen sus apuntaciones, miden el Colosseum, fotografían las Termas, deducen con números la energía gastada en traer de Egipto los catorce obeliscos, constatan la existencia de los monumentos, donde indican las guías, dan propinas, y creen en la locuaz sabiduría de los cicerones; esa Roma que comienza en la Estación, pasa en cinematográfico desfile ante automóviles veloces; y otra, la Roma del alma, como la llamó aquel admirable Lord cojo, que está fuera del alcance del Baedekery del los viajeros fugaces.

"Jorge Puccinelli Converso"

Esta Roma espiritual casi incorpórea, que tiene la rara virtud de la melancolía, que hace evocar remotas sensaciones, es como un filtro sutil y mágico que vamos bebiendo lentamente. Es el alma insepulta de la ciudad antigua que vuela entre los arcos rotos, los muros carcomidos, en los yacentes mármoles, en las estatuas mutiladas, en las tortuosas callejuelas del Imperio y de la república llenas de mendigos, de niños traposos y longevos harapientos que arrastran penosamente su miseria; es el espíritu de los siglos que resucita en las horas de luna sobre el Tévere, en los sangrientos crepúsculos, en la neblina que envuelve la ciudad como un velo, en las galerías penumbrosas, las catacumbas de los cristianos, Lylenas de leyenda y de heroísmo. Esta Roma, triste, misteriosa, pensativa, dulce y evocadora, es la que más atrae á los que venimos de la tierra de Santa Rosa y de Baltazar Gavilán.

Hoy, cuando el aire de la campiña romana envolvía suavemente la ciudad Eterna, mientras el Tévere se deslizaba ante sus 
muros seculares y el tiempo deshacía grano a grano las horas, he recibido una carta de mi madre. Todo me parecia alegre y bueno, la vida me era propicia y los árboles me sonreian al pasar. Banales afecios y rencores leves se han esfumado de mi corazón $y$ ha vuelio a nacer mi alma nueva y plácida. Hoy la Tierra es más blanda bajo mis pies, el cielo más azul sobre mis hombros; hoy es día de perdonar. He buscado á un buen amigo el Dr. Rada y Gamio:

- Hoy quiero ver a los pobres á los que no tengan nada en la vida ni esperanzas; a los más trisies, a los más infortunados. Vamos a buscar á los viejos que se arrastran entre los despojos...

$Y$ hemos jio. Un coche nos ha llevado á través de la ciudad, por avenidas amplias y verdes, por arcos legendarios de glorioso, recuerdo, por estrechas callejuelas junto á las fontanas, donde musgosos tritones soplan cilíndricos chorros, y hemos llegado al Asilo de los anormales, célebre en Italia y en Europa, creado hace veinte años por un joven médico Sante de Sanctis, con el objeto de curar y salvar á los niños que por su constitución física y moral están condenados por la naturaleza á la locura y el crimen.

Entramos al salón donde se ofrece á nuestra vista el primer grupo de niños.

¡Ah, el espectáculoedelestos inecentes condenados por una oculta mano trágica ǵ una doloresa vidal Imaginaos la infancia de una de estas criaturas nacidas con una cruel enfermedad. Pensad en la tragedia de estos niños sin infancia, sin alegría, tristes, abismados en sombrías meditaciones, atormentados continuamen. te por visiones inquielantes, luchando segundo a segundo con el torrente de sus pasiones crueles. Los hay de todas las psicologías. Ahora cantan un himno sagrado. Unos escuchan ateniamente y vibran lieno de entusiasmo ante la música, con sus ojos grandes y morenos se elevan al cielo, en éxtasis dulce, y parece que gozara con la casta caricia musical; las grandes pesiañas negras, los carrillos rosados y pelo sedoso, los ojos húmedos; no se dan cuenia de nada de lo que pasa á su alrededor y parece que su almita volara detrás de cada nota.

- Es todo un soñador, nos dice el Dr., una almita perdida para todo esfuerzo, sin voluntad sin carácter y sin acción precisa de nada, no sabe el valor de las monedas, las bota, no puede abrocharse el vestido; es un contemplativo... 
- Este otro, de pequeños ojos y fugaces miradas, es un inquieto. No puede estar tranquilo un segundo. Se fatiga de cantar, abre y ciera los ojos a cada instante, no puede fijar la atencion un minuto seguido, parece que algo le falta, que busca una cosa desconocida y remota que sus ojos no ven ni su razón conoce. Este otro debilucho, de ojos salientes, miope algo encorbado, de mirada vaga. Aquel niño de cara de viejo, de dedos corlos y llenos de arrugas que los mira desde un rincón de reojo, con duro gesto. Y el triste, este nin̄o de mirada desolada y pensaliva que parece que se diera cuenta de su desdicha que nos mira dulcemente; no canta, no sonríe, no dice una sola palabra y ahora baja los ojos y mira sin ver en un punto fijo, como si se abismara en profundas reflexciones sombrias. Su carita obalada de gastado aspecto, reposa en la mano en actitud resignada. He aquí un niño cansado de la vida, desengañado sin saber por qué, que no juega, que no ríe, a quien nada entusiasma ni despierta de su largo sueño trágico..

- Aquella niña de once años, coja, de encendido cabellos hirsuto, este pequeño de frente deprimida; aquella idiota que sonríe de todo, y a veces se queda mirando un punto desconocido del espacio y, por fin, este pobrecito que mira desde el rincón prevenido, acechando como si temiera un ataque sorpresivo y como si preparara un golpe de manos.

- Salimos de all y pasamos a un salón donde los niños aprenden á hacer labor. "Reúnenseltodos pará recibir un pequeño obsequio $y$ entonces les digo acariciando la cabecita morena del triste de esta almita pensativa y desengañada, que sufre de dolor desconocido, que busca algo que sus ojos no encuentran y ss abisma en la sombra de su espíritu.

- In nome de la mia mamma vi prego di ricevere queslo picolo regalo... (1)

- Grazie, signorino, grazie...

Y los demás;

- ¡Graziel ... ¡Grazie! ...

Uno recibe el paquete $y$ lo abro otro lo mira y lo oculta enseguida; aquel lo deja displicente, otro, sonrie; esta niña me mira agradecida é idiota, y el Triste, mi almita predilecta me mira

(1) En nombre de mi madre os suplico recibir este pequeño regalo. 
dulcemente con una mirada que parece sabia, profunda, desolada, y triste; luego baja los ojos y sigue meditando.

-Addjo -le digo- -Addio poverno, caro ragazzo, anima trisle, addio... (2)

En Villa Amalia.

Villa Amalia es una casa de salud donde se curan a los nih̄os anormales distinguidos; allí hay condes, marqueses, hijos de banqueros $\mathrm{y}$ de artistas. Llegamos al salón donde entre otros enfermitos, se encuentra el joven marqués de $X$. Tiene diez y siete años; alto, delgado, idiota, de vago mirar, sonrisa inexpresivcr, labíos caídos, ojos pequeños y estrecha frente tersa...

- ¿Cómo está el Sr. marqués?... le dice uno de los médicos. - Estos señores han venido a hacerles una vistia...

- ¡Ah, sil... los señores. . una visita...

- ¿Como se sienie Sr. marqués, está contento?...

- Bien... usted tiene un diente de oro...

Pasamos á otro salón donde una institutriz se empeña en hacer escribir á un niño de nueve años, enfermo de un horrible mal hereditario, inteligente, despierto, alegre, sano, se diría; y. sin embargo, no puede hacertebedecercá su trańs sobre la pizara. El lo ignoran y nosatzos lo miramos como se mira á los que se van se trágicamente pero no puede trazar una línea.

Es el Oswaldo de los espectros. 'Sólo que este no llegará á la juventud. Aqui parece estar hablando con los muertos. Porque todos estos pobrecitos son muertos insepultos. Ya el médico scabe cual llegará al invierno y cual se quedará en el otoño. Ellos lo ignoran y nosotros lo miramos como se mira a los que se van a internar en el abismo misterioso, sombríos de la muerte, a los que van á resolver el problema pavoroso muy pronto, á los que nos van á preceder en la ruta solitaria. Los vemos marchar de prisa, los seguimos con la imaginación, los vemos perderse por el camino ignoto por donde hemos de pasar en breve y lo saludamos antes de su partida para la Ciudad Fatal.

- Adios, señor marqués, hasta muy pronto!...

(2) ¡Adiós, pobrecito, querido muchacho, alma triste, adiós! 


\section{El Apóstol.}

He aquí un gran cristiano, alto, fuerte, generoso, alegre, lleno de fé en medio de una humanidad de niños, donde todos luchamos por no perderla, paternal con todos estos infelices á los que ha dedicacio lode su juventud y su vida, amoroso hasta la ternura, el profesor Sante de Sanctis ejerce un apostolado conmovedor y cristiano. Cuántos desdichados ha librado de la cárcel, cućntos puñales han sido arrebatados de esas manos, cuantas pasiones sombrias han sido esterilizadas al nacer. ¿Y sabéis el método que se emplea, principalmente para desarmar a estos inielices de los terribles males del espíritu? ¡El amor!

Amarlos, hacerles agradables la vida tratarlos como a hijos darles un confite un cariñoso consejo, un beso; llevarlos de la mano al campo; decirle cuan buena es la naturaleza cuan buenos son los hombres; cuan buena es la sociedad, decirles que todos deben ser buenos por que en el mundo no hay nada malo; en suma engañarlos piadosamente. A fuerza de amor y de consejos los niños sienten una especie de sugestión. A cada instante el médico les dice:

—Tú eres bueno, Guido, tú lo eres. Yo sé que tú quieres á todos, verdad?...

- Sí, si yo soybueno soy bueno . etras

- A ver Carlo, dile al Sr. grasias..

- Graz........Jorge Puccinelli Converso"

el niño que padece de mutismo se esfuerza por complacer al profesor que lo acaricia;

- Ahl No quieres decirlo; si tú sabes; si yo te he oido decir gracias... gracias...

-Graz... gra

- Ahl, tú eres malo. Carlo; tú no me quieres; dí: gracias...

- ¡Graz... zie!

|Cuanto se ha debatido, como habría los ojos, como se mesaba desesperadamente, como sufría para que su memoria le dic. tara la banal palabra.

El profesor de Sanctis, es una de las más gloriosas figuras del pensamiento italiano. Sicólogo, siquiatra, escritor pedagogo, esclarecido espíritu, alma generosa. Nacido en Umbría en 1863, fundó el asilo para niños anormales y deficientes, con la generosa ayuda de distinquidas damas italianas, en 1899. Desde en- 
tonces su vida ha sido dedicada á los niños y hoy tiene fundados tres establecimientos que forman su gran obra de redención. Ha publicado alrededor de ciento cuarenta trabajos notables sobre medicina, psicología y enfermedades mentales. Es infatigable, tiene una fe clega en su obra, y en medio de la amargura que ha dejado en su espíritu y el dolor de aquel mundo de inocentes condenados al mal, sonríe siempre y siempre espera y cada nuevo caso le da un nuevo esfuerzo. Compañero y amigo íntimo de Lombroso y de Ferri. Italia debe estar orgullosa de poseerlo. De todas partes del mundo llega el peregrinaje infinito de sus admiradores. Hombres de ciencia, artistas y escritores lo buscan. Y él con su modestia sonriente, con su alma italiana, abierta siempre al bien con su generoso espíritu dispuesto á salvar una nueva víctima. Su figura venerable se mueve en un ambiente de bondad infinita. Y se sale de su escritorio con la sensación plácida que se tiene cuando se ha estado al lado de un santo varón, de un hombre bueno y sabio, de esos que ennoblecen la especie y deben ser el orgullo de nuestra raza que como dijo alguien: "Un corazón latino vale más que un cerebro sajón".

Los colaboradores del Profesor de Sanctis.

El asilo påra niñós deficientes y anormales, está bajo la dirección inmediata del profesor. Toscano, notable pedagogo, que acompaña al maestro desde el primer día. "Como creo haber dejado entender para este difícil apostolado, á más de conocimientos profundos, de psicología pedagogía e higiene, se necesita un espíritu especial, para educar a los niños.

Sobresalen en este sentido dos médicos, uno italiano, el doctor Lanfranco Ciampi, muy joven, que empezó a hacer sus estudios médicos en el asilo, al lado del profesor, y que graduado jamás se quiso separar de él. Ciampi ama a los enfermitos como á sus verdaderos hijos, entra al asilo como el padre que vuelve al hogar, después de su trabajo. Los chiquillos lo abrazan, se cuelgan de sus piernas, le besan las manos. El los coge, los carga, los besa. Los domingos los lleva de la mano a través de avenidas y paseos y el reputado médico que debía emplear su tiempo y su renta en llevar una vida más de acuerdo con su juventud, goza con sus cojitos y sus ídiotas y los ama y los mima como un padre. 
- El otro médico es - admiraos-un médico peruano. Es un joven enviado á Europa hace cerca de tres años por la Faculiad de Medicina de Lima. Sus compañeros de mi tierra lo conocen y las gentes de letras lo aplaudieron siempre. Se acuerdan ustedes de Juan Serrano, que escribía crónicas del terruño, suaves, con aroma de un olor a tierra madura y fecunda, con una tristeza profunda, con una dulce ironía apacible? Juan Serrano es hoy uno de los médicos del Asilo y de La Villa Amalia trabaja al lado del masestro de Sanclis y ha conseguido triuntos en Europa que nos enaltece. Es Hermilio Valdizán, raro caso del carácter y de constancia, de entusiasmo y de fe. És el engreído del doctor de Sanctis y el mimado por sus compañeros de trabajo. Laborioso hasta el sacrificio, modesto hasta la temeridad, yo se que le voy a dar un disgusto con este artículo.

Ha publicado en Europa los siguientes trabajos: El Problema de los anormales.- Los Problemas Médicos del Matrimonio.-El Cocainismo y la haza Indígena.- La Sicosis Daturínica.- Perversiones Sexuales de los Primitivos Peruanos- Los Anatomistas de la Colonia.- Martín de Porras, Cirujano - Para la Historia de la Quinua.- La Meteposcopía.- Un Psichiatra del Secolo VI.- (en italiano); actualmente prepara en colaboración con el doctor Ciampi un importante trabajo para los anales de la Universidad de Roma.

Salimos del Asilo.b Los enfermitosese quedaban. Los pobres niños nos ven salir, con mirada tristei Nosotros yolvemos al mundo, á la alegría de la vida sana, á la paz del espiritu, al lugar donde ya no vemos sus caras angustiadas ni sus cuerpecitos deformes. Entraremos, de nuevo á Roma por las frescas avenidas. Automóviles cargados de belleza se cruzarán á nuestro paso, otros niños robustos sonreirán bajo las arboledas ebrios de vida y de felicidad; pero ninguno serán para mí tan amados como estos que dejo, estos tristes, los solitarios, los condenados en inocencia, los que viven en un mundo atormentado é inquieto, llenos de ensueños pavorosos, de pesadillas trágicas, de visiones horribles, de presentimientos lúgubres, estos desganados de la vida sin haberla vivido, para los cuales el breve paso por el sendero no ha tenido el casto regocijo de un juguete ni la llama luminosa de un espíritu; estos que morirán sin haber vivido, que no podrán recordar que nunca fueron niños, castigados por un delito que no cometieron y para quienes todo es sombra, sombra y dolor. 
Aquí se comprende en toda su grandeza la frase del Divino Maestro Nazareno, ¡Cristo amoroso, dulcísimo Cristo! ¿Qué reino les reservará á estos niños?

Ve aquí á las que tú amaste tanto arrastrándose en las sombras de una noche eterna, condenados á una vida de dolor irreparable; ve a tus almas electas, a los que besaron los pliegues de tu túnica, en el martirio! Pensando en el Pastor, hemos salido con un dolor inmenso, pero con el consuelo de haber llevado a los desgraciados un beso, un caramelo y una lágrima. Al salir aún resonaban en nuestros oídos las palabras de los niños:

- ¡Grazie, grazie! ...

Addio, poverini, caro ragazzi, anime dolore e tragiche, addio...

Roma, 8 de Octubre de 1913.

(Publicado en La Naclón de Lima, 21 de noviembre de 1913).

\section{II. "LAS FONTANAS"}

El agua es uno de los mayores encantos de Roma. Los siglos, por boca de las fuentes, que ponen su melancólica nota en casi todas las plazas, cantan la interminable historia de los días sepultos. Enormes borbotones surgen de marmóreos conductos y esparcen en el aire transparente la fina y leve brillantez de un casto rocío. Hay fuentes de todas las épocas. Mármoles viejos situados entre el Colosseum y el arco de Constantino señalan el lugar donde se alojaron los gladiadores sedientos después de recibir en el circo la palma de la victoria sobre el inanimado cuerpo del vencido, sobre otras fuentes se elevan obeliscos de triunfo iraídos de Egipto, que se elevan altivos con la muda majestad de faraones. En unas vibró la sátira pasquiniana, en otras se han secado los surtidores. Muchos vieron deslizarse las plácidas ó tormentosas horas papaliceas y no faltan cuáles, ya secas, recuerdan todavía el lugar donde patricios deshonestos hacían bañar á damas complacientes en la Roma Neroniana, mientras sonaban los exóticos versos de Ovidio. Sobre éstas, el tiempo ha puesto el piadoso sello del olvido.

Cuentan quienes pueden saberlo, que Sixto V, Rey de Roma, tuvo la afortunada idea, en el año seiscientos de embellecer la 
Ciudad Eterna con fuentes que dieran un nuevo encanto á su reino aprovechando para ello el agua que el sutil refinamiento pagano había encausado hacia las termas. Los manantiales que sirvieron pra limpiar los pecadores cuerpos de los romanos que se desviaron, y el agua que había lavado los aceites perfumados y disipados los vapores de fiestas, vino, casta de contactos, á cantar sus canciones entre los mármoles nuevos; así los chorros que alegraran los jardines en el Palatino fueron á, entonar su plegaria monótona en las plazas, á manera de licenciosos metidos á monjes; secáronse las termas de Tito y Diocleciano y ornáronse ias plazas de Roma, ya cristiana.

Nacieron entonces desde las fuentes humildes que se incrustan en derruídos muros, hasta las monumentales que enorgullecen las urbes, Tritones gordos y ninfas desnudas, se retuercen, soplando incansables los cilíndricos chorros; leones sedientos copian sus melenas de mármol en el espejo de las verdes aguas; gráciles náyades exhiben su blanca desnudez bajo los surtidores; caballos marinos en actitud viólenta, bajo el verde musgo nadan en cóncavas tazas. Pasquino, que ya no insulta, vive frío en su actitud secular. Lutero, encarnado por la fantasía del pueblo, en un tachino viejo vacia su barril en marmórea concha, y sarcófagos que guardaron nobles restos de patricios, yacen abandonados...

Todas estas fuentes quife embellecen lociudad inmortal y le dan ese sello característico, tan pensativo y tan amado, que vibran en los mármoles patinados que humedecen melancólicos chorros, elevan su canción al pasado y relatan, como centenarias abuelas, las cosas que viera la blancura de sus mármoles y que se retrataron en sus aguas tranquilas. A la hora del crepúsculo mézclanse los susurros de las fuentes con el lejano tañir de las esquilas cristianas, y es al conjuro de esta música suave que nos asaltan los recuerdos insepultos que vagan en el espíritu en busca de reposo, los dolores recientes y las muertas alegrías.

Artistas de todas las épocas contribuyeron á dar á esta ciudad la gracia pensativa de sus fontanas. Della Porta puso el sello de su alma florentina á la Tartarugha, Giovanni Fontana ideó los dos surtidores que se cruzan como dos brazos tranquilos en la fuente de Sixto; Próspero Breciano elevó su Moisés en la del Acqua Felice; Carlo Maderno realizó la serena y majestuosa pareja de la Piazza de San Pietro; Bernini creó la monumental de 
la Navona, aquella admirable fuente de los cuatro rios, hecha en tiempo de ignorantes geógrafos; y Salvi, Ruttelli, y lantos dejaron un recuerdo, una idea, o un mármol en las innumerables que ele. gantizan la ciudad cesárea.

Roma tiene una sicología extraña. Su alma vive en todas las cosas, en todas partes y en todas las horas. Por la mañana es agitación, vida y trabajo; al rnediodía, languidez, sopor y cansancio; en la tarde, alegría, entusiasmo, y fiesta. Pero las horas en que el alma de la ciuderd antigua sale, se pasea y vuela, al rededor de los que van a buscarla, es la hora del crepúsculo y las noches de luna. Al crepúsculo se hermanan maravillosamente el alma de las ruinas yacentes, al tañer de los bronces cristianos y la rumorosa canción de las fontanas. Quien desea sentir el espíritu de Roma, encamínase, á la caída del sol, á los barrios antiguos. En las callejuelas estrechas de muros paganos, se encaraman pequeñas ramas verdes; las ventas esperan con sus mesitas de pino á los parroquianos que luego se instalan delante del frasco de vino rojo y echan en silencio las cartas, mientras un organillo desgrana sus notas al contacto de la leve mano de un ciego, cuyo lazarillo, paliducho y esmirriado, acompaña en el violín la napolitana canción y sus ojos miran dolorosos y tristes la vida que pasa; aquella música mal tocada llega al espíritu y se filtra dulcemente; el alma se embriaga de tristeza. Una fuente vieja, verde $\mathrm{Y}$ pobre, dice cosas lentas, monótonas y extrañas, Y pasan las mozas sonriendo; los muchachos alegres y viriles; los viejos de cuarteada faz cansados, Ios exiranjeros enfermos del incurable mal de la nostalgia. El cielo se enrojece dolorosamente y en el silencio de la naturaleza el verso de Leopardi vibra:

\author{
quando novellamente \\ nasce nel cor profondo \\ un amoroso afetto \\ languido e stanco insiem, con \\ esso in petto, \\ un desiderio de morir si sente...
}

$Y$ un gran deseo de morir se sientel... Las fuentes tienen su alma como los hombres. La Tartarugha parece una chiquilla coqueta. El agua vibra allí con extraño rumor, los surtidores al caer dicen cosas banales, y su eco parece el alegre parlar de las cua- 
tro muchachas que sostienen la pompa de su taza redonda. Otras, como la del Fachino á quienes los antepasados dieron el nombre de Lutero, está mutilada y cansados cristianos llegan hasta ella á beber el agua cristalina y fresca que escancia desde hace siglos en su muro, el reformador, que en tiempos pasados interviniera en los deliciosos diálogos de Pasquino y Marforio. Otras humildisimas fuentes ofrecen su linfa para que se sacien los caballos cansados ó los obreros que van á la labor de prisa. La menos frecuentada es la de la "Boca de la Verita" que se eleva delante del templo de Vesta.

Los hombres de ahora no quieren saber nada de la Boca de la Verdad, y la pobre fuente se envejece sin que nadie llegue hasta sus aguas transparentes. La de los caballos marinos tiene la gracia encantadora de sus jardines. Las de San Pedro son majestuosas, nobles y austeras y una de las más seductoras es la de la Náyades; ninguna tiene más arte ni más espiritual movimiento.

Pero entre todas, ninguna dice más que la fuente del palacio Spada, hecha sobre un sarcófago en/el cual reposaron algún día los restos humanos de algún noble patricio. Su cadáver fue devuelto seguramente á la tierra fecundo ó al polvo fugaz, y sobre él cayó el surtidor de una fuente tranquila, como una lágrima perenne; pero también esta lagrimita le negó su caricia y la fuente secose un día. Sobre esa tumba profanada por los hombres que luego fuera secadā porl él tiempo, cayó piadosamente la tierra de los años. Muriose el musgo verde de su mármol, y dejó de beber la humanidad sedienta de sus surtidores. "Ya"la estéril fuente no da de beber á los mortales los que antes llegaran hasta ella á satisfacer su sed intensa, pasan ahora indiferentes junto á sus restos, y los cansados caminantes que se inclinaban ante el chorro que humedecía el sarcófago, van hoy en busca de más pródiga fuente...

Porque los hombres, como sugiere Kempis, cuando sienten sed van a las fuentes que tienen agua; y siguen a Cristo hasta la distribución de los panes, pero no hasta beber el cáliz de la Pasión.

Roma, 20 de Octubre de 1913.

(Publicado en el diario "La Nación" de Lima, 22 de Diciembre de 1913). 


\section{EL ALMA EN LAS SOMBRAS}

El Arie de G. Bonaventura.

El "cioble" egipcio y el parecido.

Si fué San Agustín quien afirmó que en la naturaleza no hay nada inútil he aquí lin artículo para desmentir al sabio doctor de Ipponna. Porque muchos lectores encontrarán que hablar de este arte fotográfico es como discurrir sobre futurismo del señor Marinetti ó de las virtudes teologales. Sin embargo, yo creo que en todo hay un misterio por revelarse, y en cada objeto una verdad palpitante; de manera que cada hombre discreto debe hacer un juicio de lo que ven sus ojos. En este sentido la vida no es sino un comentario de la naturaleza, mús ó menos breve, más ó menos acertado y más ó menos lógico, pero casi siempre interesado.

La fotografía que es una acusación en papel Velox sobre la vanidad universal ha dejado de ser una distracción para convertirse en un arte siendo siempre un negocio. Hasta hace poco era un comprobante simple sobre la belleza fugaz de las damas, la majestad de los señores, exhibición de trajes bien hechos y de actitudes románticas; hoy es una arte profundo, noble y pensativo. En su pásado ninguno habíía sidor más vulgar, ni más convencional ni más ridículo que este arte cle la fotografía. Las poses de los fotógrafos eran como las frases hechas de los periodistas. A una dama se le retrataba siempre con unas flores de trapo ó con un abanico, á un escritor con un libro y a un fraile con crucifijo. En el fondo, el papel citrato tenía cierta lógico y cierta síntesis de expresión, porque muchas damas no son más que flores de trapo y muchos escritores un libro. De manera que para saber á qué clases de especulaciones se dedicaba un retratado, bastaba al ojo experto pasar una mirada por la imprescindible mesa de la fotografía.

Incapaces los fotógrafos de comprender entonces -y muchos ahora mismo- que el alma no depende de los muebles, empeñábanse en amontonar objetos, cortinas y tapices, sacrificando á la persona; daban más importancia á la raya del pantalón quë á las arrugas de la frente y observaban más las luces del flore- 
ro que las de las miradas. Sacrificaban la expresión por el parecido; y en las planchas, las últimas tonalidades espirituales desafrarecían ante el verdugo lápiz del "retocador" quien no comprendíc la belleza de un rostro por expresivo que fuera, si no tenía nariz griega, boca Luis XV y ojos rasgados. Pero por fin vinieron los revolucionarios y tras ellos los verdaderos artislas, gracias á los cuales, después de la historia lamentable de la fotografía, encontramos en ello un arte sutil, lógico, sugerente y sabio; es. tilo, y artistas que se hacen pagar una copia en cien francos.

Uno de estos innovadores se encuentra en Roma: Gustavo Bonaventura, a quien en un principio se discutió tanto como á Marinatti, aunque con menos lógica y con más ignorancia. El mismo me ba contado de la génesis y peregrinación de su arte: - -Soy de Venecia, me ha dicho. Venecia es una ciudad llena de almas insepultas que vagan sobre las aguas verdes de los canales. Tengo un gran amor á la naturaleza. Me pasaba las horas en la ciudad encantada, mirando los mármoles viejos que miraban las aguas, sintiendo los crepúsculos y oyendo las mandolinatas. Pero en Venecia los contemplativos acaban siempre en gondoleros, $y$. la verdad, esto no es un porvenir. Había estado en la academia, había conocido la línea, el color la sombra y el escorzo, pero las cosas iban mal y un día dejé las artes para estudiar algo más difícil: el carácter de mis jefes en una oficina del Estado. Allí estuve un poco, pero eso nol podía seguifasi. Uusted ho sabe cuán

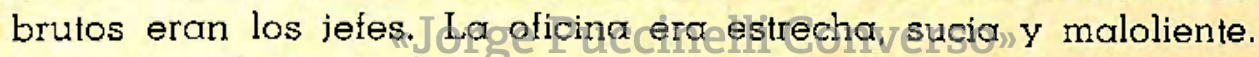
Mis compañeros de labor eran muy buenos pero muy bestias, y yo resolví dejar por otro la pequeña suma con la cual el Estado indemnizaba mis incomodidades en la oficina. Eran las cinco. Ese crepúsculo, aún entraba en el sueldo y resolví robárselo al Estado. Me fuí y compré una maquinita leal...

Entonces ya Bonaventura había ganado un premio en un concurso fotográfico. Se dedicó con entusiasmo á este arte que le atraía y en el cual encontraba algo que los otros no habían visto. Durante mucho tiempo estudió la luz, persiguió al Sol, vagó por los campos en el crepúsculo y en las noches de luna perdíase en la campiña romana escrutando al cielo desde los troncos viejos; hacía largas excursiones á la orilla del Tiber, buscando un reflejo, un paisaje misterioso, una serenidad... Sus amigos llegaron á inquietarse. Veianlo por los puentes y decían:

- ¿Querrá arrojarse al Tiber?... 
- ¿Se habrá vuelto loco?...

- ¿Se habrá hecho astrónomo?...

Pero un día el artista gritó: Eureka! Como Franklin, le había robado una verdad á la naturaleza. Sus paisajes aparecieron en un ángulo del corso Humberto. Exhibió sus primeros retratos. Los diarios empezaron a discutirlo acalorados, los pintores lo miraban de reojo y los fotógrafos gritaban á voz en cuello que se había vuelto loco. Pero la gente de buen gusto corrió a sus estudio, las revistas de arte le publicaron sus obras con grandes elogios, y la aristocracia romana corrió a sus taller. Bonaventura fue consagrado.

En qué consiste el arte del veneciano?. Sería difícil precisarlo. Hay tanta melancolía en sus paisajes, tanta alma en sus retratos, tantas ideas en sus claroscuro!. La naturaleza en sus cuadros, piensa; las personas en sus retratos, piensan; las sombras ss esfuman dialogando en yoz baja; se ignora el tiempo; las manos que él sabe retratar se pierden en un ambiente donde las sombras se mueven; nada hay banal, breve á pasajero, todo es grave, perenne, perdurable. Silencio, misterio, calma, espíritu. Y siempre una alma que mira desde el fondo ó una alma que se duerme ó una alma que piensa. A veces es sólo un perfil oscuro que se esfuma, otros, dos ojos que miran; una mano abandonada, una frente luminosa, una sonrisa imperceptible.

Según su estética, cada hombre-tiene dos almas. Una alma irretratable, intima y otraialma quelvagaoentre las facciones, alma retratable. La diferencia y la existencia de estas dos almas las comprueba diciendo:

- Si el hombre no tuviera una alma íntima; la suya y la otra para los demás, no podrían explicarse que haya criminales de tan simpático espíritu y dulce aspecto, personas en las cuales toda manifestación espiritual acusa una alma sana y santa.

- ¿De manera que una fotografía no da el retrato del alma.

- Para hablar de retrato hay que hablar de parecido.

- El parecido no existe. El parecido depende de tres cosas esenciales: la luz, las facciones y el alma visible. Tres cosas que varían constantemente. Si entendemos por parecido el parecido fotográfico, la reproducción exacta de un sujeto hay que declarar de antemano que un sujeto nunca se parece así mismo, podría parecerse el retrato á la persona si la persona siguiera teniendo la idéntica expresión que cuando se retrato y esto es im- 
posible, porque en cada segundo vivimos un nuevo estado, cam. bia la luz que recibimos, las facciones tienen una expresión en cada tono de luz; y en cuanto al espíritu, usted lo sabe, el espíritu visible, no es más que el juguete de la naturaleza; y el espíritu interno, el pensamiento el estado del alma, la imaginación, cambia tan velozmente, que tan pronto se posa en la tierra, como en una flor en un coche en una nube... En el alma lo que hay de inmutable no lo ven los otros, y lo que vemos es voluble, tornadizo y breve... De manera...

- QQue el hombre no se parece nunca a si mismo!

- No es dos veces el mismo.

Un segundo basta para cambiar al hombre y para que cambie todo lo que le rodea. En suma se retrata de una persona; el momento en que expresa su fisonomía lo que vaga de su alma visible, cuando esa alma se concreta en una expresión. Yo lo que hago es tratar de que la luz, armonice con el momento psicológico del retralado. Asi fijo el momento, pero no el alma del sujeto. Platón decía que el hombre era un cuerpo al servicio del alma. Nosotros conocemos al patrón por las órdenes que le imparte al criado... Y esas cosas son las que no podemos conocer, ni los fotógrafos ni los hombres.

En el arte de este gentil, original y habilísimo artista, pleno de juventud, ebrio de amor á la naturaleza, llama la atención una técnica misteriosa y una visión siempre triste. Todas sus obras acusan melancolía, "honda, Palorimal idisimulado,Omisterio, silencio, serenidad que invita la contemplación pensativa, á la inmovilidad penumbrosa de sus paisajes, la crueldad de sus noches de luna; como pintor se habría parecido á Rembrandt aunque á veces tiene la grácil coquetería de Wateau donde hojas largas y finas caen amorosamente sobre sus cuerpos joviales, pero más que todo sus visiones del campo crepuscular semejan á Meisonnier, la ruda sencillez de sus labradores, la mansedumbre de sus bueyes, al crepúsculo, bajo los rayos oblícuos del sol, la encantadora poesía virgiliana, la serena majestad de la noche, él ha sabida ponerlas en sus copias.

Donde se puede encontrar algo de su espíritu es en la fotografía al monumento de Garibaldi. Allí ha interpretado la epopeya del siciliano, la grandeza de su genio avasallador y pujante, la rudeza de su carácter convigto, todo vibra en esta fotografía expresiva y marmórea como un verso de D'Annunzio. En ne- 
gro dibújase la silueta del monumento con la severidad de las clásicas líneas; sobre él, como sobre un molde, yérguese el luchador, cabalgando el audaz caballo de pecho duro, pasan nubes tormentosas como detenidas ante su grandeza. En sus fotografias no se sabo si se adivina la hora.- Hay un misterio del tiempo. Los personajes de Bonaventura viven en un ambiente donde el reloj de la arena no se deja sentir. Sus almas "visibles" como él las llama, no se sabe si han sido o si serán. Son almas solamente que se pierden en la eternidad.

Después de amena charla con el artista, salgo de su estudio, de un exquisito buen gusto, mientras los retratos acechan entre los marcos y luego me pierdo en las calles de Roma, donde la humanidad se agita entre las sombras a manera de ideas en un cerebro que pensara. Rumio aún la frase: el hombre es un cuerpo al servicio de una alma, la mastico de mal humor, y la irago, por no hacer al señor Platón el grave desaire de desmentirlo...

Roma. Octubre 29 de 1913.

(Publicado en "La Nación" de Lima, 21 de enero de 1914)

IV EL VIAJE DE IA GIOCONDA.-LA TRISTEZA DE UNA VIDA TRUNCA

Para "La Nación"

París estaba, artísticamente, bajo la advocación de dos mujeres á cuya sombra se acogía su espíritu tranquilo como Cartago al velo de Tamt. Aquellas dos divinidades eran el símbolo de ese pueblo sabio y sensible: la forma armoniosa é inmaculada de Afrodita y el espíritu insondable y plácido de Mona Lisa; el mundo desfilaba en el Louvre ante el pedestal de Venus y comulgaba luego en el Altar de la Gioconda. Estas dos hermanas armoniosas eran la carne y el espíritu, la forma y la idea, el cuerpo y el alma, y formaban una sóla vida artística que protegía desde las orillas del Sena a la humanidad que se purificaba en la eucaristía del arte, de las cosas intangibles y hondas, por encima de la torpe miseria de la vida. 
Extranjeras, ambas habían llegado á ser parisienses. En su altar educáronse las generaciones y la religión de su belleza difundida llegó á ser universal. Ellas vieron pasar el innúmero peregrinaje de los hombres, sintieron las miradas de todos los ojos y las fiebres de iodos los entusiasmos. Mas un día truncóse el paralelismo de esas, vidas y una de las dos hermanas desapareció, la Gioconda no volvió á sonreír y París vistió luto por mucho tiempo.

La divinidad había abandonado su trono y en la tortuosa ruta de un viaje desconocido, perdióse en alas de un misterio impenetrable. Sólo quedaba el cuerpo frío, el rostro sin pupilas, la pagana forma de la manca inconsolable. Venus quedóse dueña de París. Desde aquél día algo faltó á la ciudad encantada y al espíritu francés faltaba una de sus más dulces complacencias; porque para aquella ciudad inquieta, la mirada de la Mona Lisa' era como un refugio de espiritualismo en medio del cotidiano tormentoso. Los visitantes del Louvre, al salir ya no tenían ese gesto de peregrinos que han bebido en la fuente fresca y tranquila; ya en el templo de las bellezas no existía la sonrisa inefable, la gracia encantadora, la mirada profunda, las manos mórbidas, la paz misteriosa del paisaje florentino. Y notábase en los que salían un vago gesto de melancólico desencanto.

De vez en cuando aparecían en los diarios una vaga esperanza a dos columnas, más aldía siguiente se callaban, y como nadie sabía el parádero todosc señalában algúno nuevo camino.

Por fín calláronse los diarios, ennmudecieron los artistas y se buscó algo que hiciera desaparecer el recuerdo lacerante. Todo París se echó en brazo del tango argentino en medio de cuyas rítmicas volutas, los más horribles recuerdos se disipaban. Los que no esiaban á la altura del tango se dedicaron á inventar pistas y á imaginarse al ladrón. Se creó una literatura giocondinesca. D'Annunzio empezó á escribir un libro: El hombre que ha robado la Gioconda...

\section{El ladrón en la tantasía parisién.}

Siendo la Gioconda una obra "invendible", creíase que el ladrón no fuese un pobre diablo. Se decía que la obra había sido robada por algún "ser superior", por algún artista, un excéntrico 
ó un desequilibrado. Para unos, el ladrón era una especie de Monsieur de Phocas, que obsesionado por la sonrisa de la obra Leonardesca, la había robado para contemplarla solo y en paz. Se habló de un lord inglés, uno de esos antiguos personajes de Oscar Wilde, morfinómano y splinático. Dijeron algunos que un millonario yanqui la había llevado a su país; otros hablaron de un pintor francés y quienes de un iconoclasta judío. Para éstos el ladrón era blanco, rubio, depilado; para aquellos, moreno, pálido, de barbas; para algunos era un hindú; pero todos estaban de acuerdo en que no era un hombre vulgar sino un espíritu exquisito y refinado, capaz de comprender la maravilla de Leonardo. Era un "caso" de sentimentalismo artístico, de neurastenia aguda, de monomanía, de alguna de esas enfermedades que lo ponían muy por encima, moralmente de los cleptómanos de oficio, de los apaches de boulevard, o de los monederos falsos. Por eso cuando se tuvo la confirmación del hallazgo todos se preguntaron: -¿Quién es el ladrón?...

Pequeños comentarios sobre el ladrón de la Gioconda, o sea sobre Vicente Peruggia.

Oh, desencanto, oh, ilusiones rotas de la vida, oh, duro choque de la realidad que nos sorprende- Lords que caen del encumbrado sitial de la fantasía, obsesionados que no existen, neurasténicos que no roban, iconoslastas que no destruyen, Monsieur de Phocas que duerme en los anaqueles terrosos de alguna librería. Ninguno de esos señores ha robado la divina obra de Vinci. El ladrón... es un hombre. Un hombre como cualquier otro. Bajito, metido en carnes, sucio, cursi, estúpido, necio y bellaco. Vulgar en el tamaño que no es ni alto ni bajo. De una mediocrecidad repugnante. De una imbecilidad ofensiva. Ni abiertamente lombrosiano, ni claramente normal; ni tan bruto como para dejarse coger al cometer el robo, ni tan hábil para librarse de la cárcel con una respuesta atinada. Carece de todas las agravantes morales que le pudieran disculpar el robo, no es poeta, ni pintor, ni periodista. ¿Con qué derecho se robó la Gioconda?. En fin, es un cretino, que no merecía haber tenido entre los muros húmedos de su buhardilla, y bajo las telarañas de su colchón, la obra maestra de los siglos, la imagen de aquella mujer á la cual el divino Leonardo no le fué dado tocar con sus sabias y expertas manos. 
De las torturas y malandanzas de la Gioconda durante los dos años de su ausencia, y al lado del cretino.

El ser innoble, catalogado ya en la cárcel de Florencia y que en trato de gentes de bien, llamóse Vicente Peruggia, ha narrado la historia de su robo: él era empleado en el Louvre, y aunque de arte no sabe absolutamente nada, indignábase siempre de que los extranjeros aplaudieran las obras más celebradas del Museo, entre las cuales habían muchas italianas. A él le habían dicho que Napoleón había sido un señor muy poderoso pero muy ladrón, que no se ocupaba de otra cosa que de robarse cuadros, y que muchos, todos los del Louvre, eran robados a Italia por Napoleón. Entonces nació en él el deseo de venganza. Concibió el robo, una mañana, aprovechándose de que no le veían, descolgó del muro la divina tela y se la ocultó bajo la blusa, como quién se roba un par de zapatos. Mona Lisa, bajo la blusa de Vicente, atravesó las calles de París para ir a alojarse debajo de una cama inmunda. Y allí ha estado la divina mujer, durante dos años, en la innoble compañía de ratas, arañas, humedad y mal olor. Un día emprendió viaje á su tierra. Iba en una caja de humildísimo. abeto, junto con la ropa sucia del patriota que la conducía, sobre ella había zapatos rotos, calcetines usados y otras prendas de vestir de másanterioridade De Callí pasó á la Prefectura y recuperada "pof das pautoridades policjales $\mathrm{Y}$, artistas, pudo ver la luz en la Galería de los Uffici, en Florencia, aquella patria de genios, de donde saliera en un lejano día. Florencia envió aquél mismo día al Palacio a unos cincuenta mil florentinos que desfilaron ante el cuadro, en desfile caballeresco, en homenaje a la obra y al genio italiano que le diera vida. Aquella sola manifestación, de tan delicada cortesanía, sería suficiente para desagraviar a Mona Lisa de los vejámenes sufridos en poder del Peruggia. La obra vendrá en breve a Roma y se exhibirá en la Villa de Médici. Toda la ciudad se prepara a recibirla y a rendirle pleitesía, en tanto en París se organizan grandes fiestas para celebrar su vuelta, el día que atraviese de nuevo los pasillos del Louvre, el día en que su hermana Afrodita la vea pasar, en cortejo triunfal, por el mismo sitio por el cual, en una mañana: trágica, sus ojos sin pupilas no la descubrieron bajo la blusa azul de aquel bellaco... 
Los honores en Roma.

Periodistas, universitarios, hombres de fama e ingenio, han pedido al Ministerio de Relaciones que la Gioconda sea expuesta en esta ciudad. El sábado aparecerá la obra en Villa Medici. Sabido es que Leonardo de Vinci dió sus últimos toques al lienzo, en Roma. Aquí, pues, donde por primera vez se insinuara su sonrisa, va a ser admirada, aquí, en la paz de la ciudad antigua, donde Leonardo fijara la dulce placidez, la casta mirada, aquel ensueño cándido, el espíritu inmutable, lo que hay de más puro y divino en una alma selecta, la suave insinuación de una sonrisa...

Roma, 1913.

(Publicado en el diario "La Nación" de Lima, sábado 24 de enero de 1914).

\section{EL ESPIRITU DE ROMA.- LA EXPOSICION DE FLORES}

\section{Para La "Nación"}

\section{Biblioteca de Ietras}

En las tardes de otoño romano llenas de nubarrones sombríos y de tempestades en gestacion, en la obscuridad sinestra del invierno que se avecina, cuando las tardes mueren jóvenes y las estufas dan el calor que la naturaleza niega, mientras noviembre hace pensar en los muertos y a la lluvia enciende en el cementerio los primeros fuegos fatuos, abre sus puertas el Palacio de $\mathrm{Be}$ llas Artes, para exhibir las flores más bellas de la estación. Muchas gentes que se dedican a este romántico apostolado de las flores, eligen las más hermosas y las envían al torneo sentimental. Y así han ido a reunirse democráticamente, en los espléndidos salones del palacio, las más raras y delicadas flores. Finas florecillas raquíticas de conservatorio, anémicas, como damas enfermas a las cuales el menor airecillo hace morir; enormes y sangrientas, conservadas a pleno sol; minúsculas y celestes, enviadas de la campiña; aristocráticas, traídas de las mansiones de los príncipes; cuales arañas rojas, de cinco pétalos, acechan como manos iracundas; otras, del obscuro color y misterioso aspecto, 
como viejas brujas; éstas, sencillas y apacibles, como niñas castas; algunas, blancas y buenas, como santísimas hostias; cándida y polícromas, rebosantes de vulgaridad; pensamientos en forma de calavera desdentada; violetas de Parma, que parecen hechas con viejas y descoloridas sedas celestes; y no pocas de colores vivos y chillones como banderas de países remotos. Las hay lánguidas, como una canción, puras y marmóreas como un verso, y gráciles como una onda serena. Todas esperan en los salones, donde un jurado, sabio en perfumes, en colores y en abonos, las consagrará como reinas de una fiesta quimérica.

El tiempo ha sido espléndido, la numeorsa concurrencia, los premios sugestivos. Pieles, plumas, monóculos, humo de cigarrillos orientales, calorcito de estufa estimulante de las amenas charlas, nada ha faltado en el certamen. Sin embargo, la exposición ha tenido una vida breve y fugaz, ha sido como una vanal fiesta de sociedad. No parecía que se tratara de flores, sino de mujeres frívolas y mundanas. Se puede decir que la exposición ha fracasado. ¿A qué se debe este fracaso?... Ni a los organizadores ni a los concurrentes, ni al clima, ni al público. Se debe a las mismas flores. A la tristeza de las flores. Porque en Roma las flores son tristes, como las personas. No podría precisarse donde reside esa trisleza pero es evidente que hay algo muy sutil en las flores, que escapa $a$ nuestras miradas torpes. Ya a alguien se le ocurrió decir que las florestenian alma,perofue una idea de poeta y estos señoresr están muỵn desprestigiados como sicólogos. Los claveles romanos son tan bellos como los de España, pero los claveles andaluces son alegres, y estos son melancólicos. Las rosas de Roma son tan hermosas como todas, pero son tristes. Los crisantemos, de tan exótica belleza, no son bien queridos por los habitantes de la ciudad augusta, y muchas familias no se atreven a comprarlos porque traen desgracia. Aquí las flores parecen flores de cementerio, melancolía, frialdad de muerte, perfume lánguido de tumbas, vaga entre los pétalos. Se crée que una flor debe cubrir siempre una tumba recién abierta, o morir entre las manos de un cadáver tibio. Y sea por el prejuicio el poco uso que las dan, estas flores son tan desoladas, que parece que nunca hubieran visto un cielo descubierto y azul, ni recibido la alegre caricia de un rayo de sol, ni el beso de una gota de rocío, cristalina y fresca. Ya no existe la guirnalda pagana ni los romanos se coronan de rosas. 
Y hay una estrecha relación entre las flores de Roma y los romanos. Dijo Anatole France que Roma era tan alegre que hasta la muerte reía. No lo creo. La alegría de los verdaderos romanos, sus canciones, la voz doliente de sus organillos, el cantar de los ciegos, por las tardes, mientras muere el crepúsculo, no es sino una mueca de dolor disfrazada. Y no puede ser alegra un pueblo sobre el cual pesa tanto la Historia. Ya he dicho que hay dos Romas. Una Roma moderna, con tranvías eléctricos, fábricas y automóviles, cabarets, teatros y cinematógrafos, y otra, la Roma antigua, la verdadera, la que conserva su alma y su carácter inmutable y eterno. Y esa Roma verdadera es triste, con desoladora tristeza. Entre las ruinas terrosas que rastreras hiedras lamen y arbustillos circundan, entre las columnas rotas, los derruídos palacios imperalicios, y las soberbias mansiones desplomadas, se vive una vida de ensueño perenne y fantástico. La constante evocación del Pasado, el hálito de las cosas sepultas, las glorias conquistadas, las decapitadas columnas gigantescas, el susurrar monótono de las fuentes y el Tíber que se desliza sin rumores, todo induce a la melancolía y al dulce evocar. Entre todas estas cosas, los verdaderos tipos de romanos, muchos de los cuales conservan aún un perfil latino, un gesto de patricios, una frente de filósofos o un cuerpo de atletas, pasan cantando, cantan siempre, pero su cantar no es expresión de alegría, sino lenitivo de dolor. Para ellos lel cantar es una droga, Sel placer un remedio $y$ el sueño unjbiene Puccinelli Converso»

Todo habla en esta ciudad maravillosa de la muerte. En los antiguos palacios patricios, viven modernas generaciones de sencillas gentes. Lo que fuera tumba de unos es hoy cuna de los otros. Sarcófagos de mármol sirven de lecho a muchas fuentes sobre las cuales escancían el agua, las generaciones que se levantan. Los templos son verdaderos cementerios. Es difícil encontrar un templo de Roma que no tenga diez o veinte cadáveres de papas o de personajes célebres, cuyos restos guarda y decora el mármol frío. La cruz con sus brazos abiertos corona casi todos los obeliscos y así, el arte mismo no puede liberarse de una marcadísima tendencia a lo pasado, limitando el vuelo de muchas almas jóvenes, que antes de desenvolverse, ya están aprisionadas por el hálito de un arte sepultado, e inadaptable a los tiempos que corren. $Y$ es tan grande el atractivo que tiene la Roma antigua, es tan dulce pensar en los pasados tiempos de esta cuna 
de civilizaciones, es tan adorable ver deslizarse el Tíber, bajo los puentes seculares, imaginando a las enormes manadas de esclavos etíopes, o egipcios que las construyeron, es tan maravillosa una noche de luna en el Colosseum, sentado en la arena que regaran los cristianos, bajo las garras afiladas de los leones de Libia, pasar por los mismos mármoles escalinados por donde pasaron los Césares en aquellos días de fiesta de sangre, tan amados y lejanos!

Todo esto me sugieren las rosas de la campiña y los crisantemos que esperan el premio del concurso. Paso delante de todas estas flores tristes, enfermas, no sé de qué mal, sin perfume y $\sin$ alegría. Desfilamos delante de flores blancas y leves; moradas, como sangre que se coagula; amarillas, como rostros de tuberculosos; más allá se alargan sobre sus gentiles tallos claveles encendidos, a su lado, violetas de Parma de sucio color celeste y rosas arrogantes y finas, y las palmeras de América, llenas de salvaje majestad, cobijan a las pequeñas flores, como madres cariñosas que acojen a sus hijos bajo sus brazos fuertes. Y salí desconsolado, porque las flores tristes y sin perfume son como "alma sin amores", como mañanas sin sol, como hogares sin niños...

Roma, 10 de Noviembre de 1913.

(Publicado en diario "La Nación"a Lima, 30 dè Enero de 1914.) "Jorge Puccinelli Converso" 